\title{
ПОТЕНЦИАЛЬНАЯ РОЛЬ НАРУШЕНИЙ КИШЕЧНОЙ МИКРОБИОТЫ ЧЕЛОВЕКА В КАЧЕСТВЕ ИНИЦИАЛЬНОГО ЗВЕНА ПАТОГЕНЕЗА ЗАБОЛЕВАНИЙ ИММУННОЙ СИСТЕМЫ, А ТАКЖЕ ЗАБОЛЕВАНИЙ, АССОЦИИРОВАННЫХ С НЕЙРОВОСПАЛЕНИЕМ
}

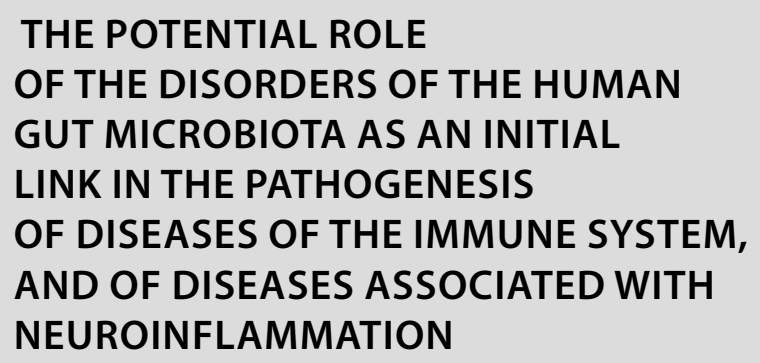

I. Eremenko

Summary. The investigation of various aspects of pathogenesis of immune diseases (for example, reactions of hypersensibility and different types of allergy) lead to understanding the fact of participation of gut microbiota at the modulation of normal functioning of the immune system. There are new arguments for the role of maternal immune activation (MIA) in the pathogenesis of nervous and psychical disorders of the children, and also the medical scientists explore the role of the gut microflora at forming the neuroinflammation and it's possible participation at the pathogenesis of neurodegenerative disorders. However, there are a lot of new questions and argues and very little amount of answers. The review of last results in the problem of connection between gut microbiota and immune system have a purpose of critical assessment of it and the popularization of one of the most perspective trends in the immunopathology.

Keywords: allergy, immunopathology, microbiota, maternal immune activation, neuroinflammation.

\author{
Еременко Иван Иванович \\ Первый МГМУ им. И.М. Сеченова Минздрава России \\ (Сеченовский Университет), Москва \\ dvavani@mail.ru
}

Аннотация. Изучение разнообразных аспектов патогенеза иммунных заболеваний (реакций гиперчувствительности, различных форм аллергии) многочисленными авторами привело к пониманию факта участия микробиоты кишечника в поддержании адекватного функционирования иммунной системы человека. Появились доказательства роли материнской иммунной активации (МИА) в патогенезе нервных и психических расстройств у детей, исследована роль микробиоты кишечника в формировании нейровоспаления и возможном участии микрофлоры в патогенезе нейродегенеративных расстройств, однако с появлением новой информации разгораются новые споры и появляется больше вопросов, чем ответов. Обзор последних исследований по теме взаимодействия кишечной микробиоты с иммунной системой преследует цель критического рассмотрения и популяризации одного из наиболее перспективных и изучаемых мировой медициной взглядов на иммунопатологию.

Ключевые слова: аллергия, иммунопатология, микробиота, материнская иммунная активация, нейровоспаление.

\section{Введение}

K ишечная микробиота человека, представленная, по разным оценкам, приблизительно 395 видами бактерий, в основном анаэробных, интересна с точки зрения самых разных ее влияний [1]. Существуют исследования, говорящие о значимой роли этих микроорганизмов в функционировании человеческого организма - подтверждена взаимосвязь метаболитов микрофлоры с развитием атеросклероза (важно участие триметиламиноксида - метаболита микрофлоры, поступающего в кровоток и вызывающего множество эффектов в эндотелии сосудов и потенциирующего развитие

окислительного стресса) [2], а также в развитии патологий нервной системы (речь идет о возможной роли микрофлоры в патогенезе нейродегенеративных расстройств) [3]. Возможности микрофлоры с точки зрения влияния на иммунную систему достаточно велики: следует сказать, что микробиом кишечника, а так же кожи и слизистых оболочек, считается фактором неспецифической защиты организма вследствие формирования на данных структурах мощной антагонистической по отношению к патогенным бактериям популяции микроорганизмов, реализующих колонизационную резистентность [4]. Этот барьер играет важнейшую роль в качестве первого препятствия для инфицирования организма в области 
наиболее распространенных входных ворот инфекции. Иммунная система не распознает представителей нормальной микрофлоры в качестве чужеродных объектов - этому способствует и относительная отграниченность микрофлоры от внутренних сред (в норме), а также приобретенные данными бактериями в ходе эволюции приспособления к симбиозу, выраженные в уменьшении их антигенности и иммуногенности. Это обусловливает также и негативные возможные последствия для макроорганизма: в случае нарушения разграничения между микрофлорой и внутренними средами развиваются тяжелые инфекции, которые могут стать летальными как раз вследствие упомянутых свойств нормальной микрофлоры.

Приведенные выше данные о неоднозначных свойствах человеческой микрофлоры приводят к необходимости детального выяснения всех возможных влияний бактерий на человеческий организм, и, что является предметом данного обзора, с точки зрения воздействия микробиоты на иммунную систему. Представляет особый интерес возможная роль микроорганизмов в патогенезе реакций гиперчувствительности (в основном - в развитии аллергии), хронического нейровоспаления, возможная роль в формировании иммунной системы с детского возраста и определении адекватности и эффективности иммуных реакций, а также влияние микробиома на иммунную систему беременных женщин.

\section{Взаимосвязь микробиоты кишечника с реакциями гиперчувствительности}

Механизмы развития различных форм неадекватного иммунного ответа организма на введение разнообразных антигенов до конца не ясны. С точки зрения обозначенной проблемы кишечный микробиом может играть важную роль в развитии пищевых аллергий, а также потенциировать развитие экземы. Эти данные были получены европейскими исследователями в ходе анализа микрофлоры кишечника у группы детей, имеющих повышенный риск развития аллергических заболеваний [5]. Исследование было комплексным - дети находились на искусственном вскармливании с добавлением неперевариваемых олигосахаридов (вещества, усваиваемые определенными представителями микрофлоры). Было выяснено, что физико-химические свойства фекалий у детей, получающих в качестве добавки олигосахариды, ближе к показателям фекалий детей, находящихся на грудном вскармливании, чем к аналогичным показателям у детей, находящихся на искусственном вскармливании без добавления олигосахаридов. В конечном итоге исследователи выявили, что у детей, у которых к 18 месяцам жизни развилась экзема, в течение первых 26 недель жизни в кишечнике аномально выросли уровни содержания бактерий родов Enterobacteriaceae и Parabacteroides, и одновременно снизились уровни потребляющих лактат бактерий родов Eubacterium и Anaerostipes, а так же снизилось содержание бутирата и возросло содержание лактата. Эти данные можно использовать в качестве отправных в продолжении более детального исследования патологических изменений микрофлоры у лиц с аллергией, а также в разработке средств, способных скорректировать данные изменения.

Более детальное изучение молекулярных механизмов влияний формирующейся в организме младенца кишечной микробиоты на развитие иммунной системы и адекватности ее функционирования представлены в работе van den Elsen et al. [6]: авторы рассматривают грудное молоко как ключевой фактор для поддержания нормального состава микрофлоры: акцент сделан на то, что с грудным молоком в ЖКТ ребенка попадают определенные виды микроорганизмов (родов Lactobacillus, Staphylococcus, Enterococcus, Bifidobacterium и прочие), и одновременно с этим в составе материнского молока присутствуют такие антибактериальные вещества, как $\lg$ А, кинуренин, лактоферрин (их список достаточно обширен и не до конца изучен) - они поддерживают избирательность заселения кишечника младенца, формируя наиболее приемлемую для него микрофлору. Аналогичным образом в предыдущей работе авторы модулировали развитие микроорганизмов посредством неперевариваемых олигосахаридов у детей, потребляющих коровье молоко - добавление подобных веществ создает своеобразную селктивную среду в ЖКТ, формирующую приближенное к нормальному соотношение содержания бактерий. Представители некоторых видов (Lactobacillus и Bifidobacterium) синтезируют короткоцепочечные жирные кислоты, которые способны стимулировать синтез TGF- $\beta$ (трансформирующий фактор роста- $\beta$ ) эпителиальными клетками кишечника и посредством этого влияния активировать Т-регуляторные клетки (T-reg cells), которые, в свою очередь, контролируют адекватность иммуного ответа организма на потенциальные аллергены. Авторы также упоминают лиганды ариловых углеводных рецепторов, синтезируемые микроорганизмами, которые связываются с рецепторами на врожденных лимфоидных клетках третьего типа (ILC3), активируя в них синтез ІІ-22, один из основных эффектов которого - укрепление кишечного эпителиального барьера (посредством активации усиления секреции антимикробных веществ клетками Панета, а также слизи бокаловидными клетками), что также значимо для предотвращения развития аллергии. Существуют данные о механизмах, опосредованных катаболизмом триптофана бактериями и секреции ими метаболитов, способных также влиять на регуляторные Т-клетки, а также о молекулярных механизмах активации иммуных клеток посредством молекулярных паттернов, ассоциированных с микроорганизмами (microorganism-associated 
molecular patterns), таких, как липополисахариды клеточной стенки бактерий - полагают, что подобные взаимодействия между иммуной системой и микрофлорой способны настраивать адекватность как врожденного, так и адаптивного иммунитета [7].

Приведенные молекулярные механизмы возможных влияний микробиома на иммуную систему, а так же наличие взаимосвязаных с этой проблемой вопросов делают необходимым продолжение изучения конткретных видов микроорганизмов, а также их соотношения в составе кишечного микробиома и их роли в развитии неадекватного иммуного ответа на различные пищевые потенциальные аллергены [8]. Ранее изученные и потенциальные возможности микрофлоры необходимо использовать в качестве целей для терапевтического воздействия и дальнейшей нормализации нарушенных функций иммунной системы.

\section{Нейровоспаление и кишечная микробита}

Тема нейровоспаления - одна из самых обсуждаемых в научном сообществе в последние годы $[9,10,11]$. Неслучайно именно эта тема вызывает самые горячие споры - она во многом создаёт фундаментальные теоретические позиции для развития новых гипотез, в известной степени опровергающих укрепившиеся и популярные теории, объясняющие механизмы развития таких сложных заболеваний, как болезнь Альцгеймера, Паркинсона, большое депрессивное расстройство [12]. Так, некоторые авторы открыто говорят о необходимости пересмотрения, или, по крайней мере, дополнения теории о нарушениях в конформации и свертывании предшественника бета-амилоидного белка - основной на данный момент теории, объясняющей патогенез болезни Альцгеймера. Они предлагают новый, достаточно необычный взгляд на эти процессы: в качестве инициального звена патогенеза расстройств нервной системы они рассматривают процессы, происходящие в кишечной микробиоте. Ключевые аспекты этих патологических процессов заключаются в различных нарушения состава микрофлоры или функционирования бактерий отдельных родов, что влечет за собой изменения в функционировании иммунных клеток в кишечной стенке (как было подробно объяснено выше, существуют доказанные молекулярные механизмы данной взаимосвязи например, воздействие на ILC3 посредством лигандов ариловых углеводных рецепторов и стимуляции II-22, а также воздействие на регуляторые Т-клетки) [6]. Данные влияния индуцируют развитие хронического воспаления в кишечной стенке, и, соответственно, происходят выраженные изменения состояния иммунной системы: в крови повышаются уровни таких провоспалительных цитокинов, как II-1, ФНО (фактор некроза опухоли), ин- терферон-гамма, и т.д. Некоторые из этих веществ способны проникать через гематоэнцефалический барьер, воздействуя на глиальные компоненты нервной ткани. Активация медиаторами воспаления данных клеток влечет за собой синтез новых веществ, которые воздействуют на нейроны и на ближайшее глиальное окружение, что влечет за собой специфическое воздействие непосредственно на нервные клетки и их функции, а также обуславливает распространение подобного ответа на обширных участках центральной нервной системы [13].

Морфологический субстрат нейровоспаления многими авторами рассматривается в основном как результат специфической активации микроглии и изменения ее структуры и функционирования [14]. Так, доказана способность липополисахарида (LPS), содержащегося в грамотрицательных бактериальных клетках, а также некоторых провоспалительных цитокинов значительно изменять работу микроглии и астроцитов, переводя ее из физиологического состояния «наблюдателя» в активированное защитное состояние - морфологически это проявляется в серьезном изменении структуры клеток - из нормальных глиальных клеток с множеством тонких отростков они превращаются в гипетрофированные, крупные клетки с толстыми отростками. Это происходит вследствие специфической активации нескольких сигнальных путей, один из которых - внутриклеточный путь, связанный с семейством митоген-активируемых протеинкиназ (МАРК) с последующей активацией ядерного фактора (NF-kb) и синтезом провоспалительных интерлейкинов. Что особенно важно, такая специфическая активация также приводит к формированию внеклеточных микровезикул (эктосом), содержащих обилие самых разнообразных факторов - ферментов, набор различных микроРНК, эндосом-специфических белков, и провоспалительных цитокинов. Микровезикулы расссматриваются в качестве основных посредников в межклеточном взаимодействии - предполагается, что именно благодаря им возможно активное воздействие глиального окружения на нейроны и контроль многих функций нервной системы, а также появляются предположения, что набор специфических микровезикул можно рассматривать как клинико-диагностический маркер некоторых нервных и психических патологий.

Описанные молекулярные механизмы нейровоспаления и влияний микробиома на этот процесс способны в перспективе объяснить патогенез таких сложных заболеваний с невыясненной этиологией, как большое депрессивное расстройство, нейродегенеративные заболевания, боковой амиотрофический склероз, а также появляются данные о влиянии кишечного микробиома на восстановления ЦНС после различных травм спин- 
ного мозга $[15,16]$. В данном случае иммунная система является посредником между кишечным микробиотой и нервной системой и может служить дополнительной мишенью для терапии и профилактики указанных заболеваний.

\section{В^ияние кишечной микробиоты на иммунную сИстему \\ беременной женшины}

В контексте проблемы состояния иммунной системы беременной женщины, ее возможой патологии и воздействия на организм плода следует сказать о специфическом состоянии, названном "материнской иммунной активацией" [17]. Оно характеризуется повышением в крови женщины уровней некоторых провоспалительных цитокинов (основные - II-6 и II-17) и других биологически активных веществ. Не до конца понятно, какие именно причины обуславливают подобное состояние иммунной системы: одним из возможных этиологических факторов является дисбиоз кишечника беременных женщин. Нарушение адекватного соотношения микроорганизмов приводит к сдвигу в сторону патогенных видов и вызывает воспалительные изменения в кишечнике. В свою очередь циркулирующие провоспалительные вещества (упоминаются, помимо интерлейкинов, также липополисахариды бактериальной стенки) могут через пока не до конца понятные механизмы воздействовать на нервную систему плода. Особенность данного патологического процесса в том, что он зачастую идиопатичен и ассоциирован с серьезным увеличением риска развития таких психических патологий, как аутизм и шизофрения, у новорожденнного [18]. Ниже рассмотрены некоторые механизмы материнской иммунной активации, а также их взаимосвязь с кишечным микробиомом.

К молекулярным механизмам материнской иммунной активации и влияния на организм плода относят возможное изменение экспрессии некоторых генов в ЦНС плода - конкретно некоторые авторы упоминают гены сигнального пути NRG-ErbB (материнская иммунная активация способна менять уровень экспрессии гена белка NRG1 и его рецептора ErbB4), а также гены дофаминового D2 рецептора. Полагают, что данные изменения играют значимую роль в потенциальном развитии психических нарушений у ребенка [19].

В экспериментах на приматах была выявлена корреляция между материнской иммунной активацией и повышением уровня дофамина в полосатом теле у потомства в позднем подростковом периоде. Данные изменения сходны с таковыми у людей, страдающих шизофренией, и в совокупности с вышеуказанными механизмами могут принимать участие в патогенезе данного заболевания [20].
Материнская иммунная активация и ее взаимосвязь с нервной патологией наглядно продемонстрирована в эксперименте на мышах. Авторы вызывали различные воспалительные состояния введением в организм самки инфекционных агентов (такого как вирусная миметическая полиинозин-полицитидиловая кислота (Polyl: C), а также ассоциированные с дисбиозом кишечника) в наиболее значимые для развития нервной системы плода периоды гестации в организме беременной самки и наблюдали за состоянием потомства [21]. Была выявлена корреляция между иммунной активацией материнского организма и развитием различных подобных психическим нарушениям состояний (отклонения в социальном поведении, отсутствие контактов с сородичами) у потомства. Данную модель предлагается использовать как одну из наиболее перспективных для изучения аутизмоподобных нарушений и их взаимосвязи с иммунной системой и микробиомом.

В исследовании с относительно небольшой выборкой авторы изучали эффективность применения пересадки микробиома от здорового донора детям, больных аутизмом [22]. По результатам данной работы был сделан вывод о достаточно серьезных позитивных сдвигах в поведении и состоянии пациентов, авторы предлагают провести более масштабные исследования данного вопроса.

Особенно интересен факт позитивного профилактического эффекта применения пероральных пробиотиков у беременных женщин в предотвращении дальнейших психических проблем у потомства [23]. В экспериментах на мышах было показано, что введение пероральных пробиотиков беременным самкам значительно снижало риск проявления аутизмо-подобных нарушений у потомства. Факт позитивного влияния пробиотиков подчеркивает роль кишечника и микробиома в патогенезе развития материнской иммунной активации и в ассоциированных психических расстройств у потомства. Необходимо проведение дополнительных исследований и рассмотрение перспективы введения пероральных пробиотиков беременным женщинам в качестве профилактического средства.

\section{Зак^ючение}

Представленные в обзоре доказательства значимости адекватного взаимодействия кишечной микрофлоры с иммунной системой в предотвращении развития таких патологий, как реакции гиперчувствительности, а также других расстройств иммунной системы и ассоциированных с ними заболеваний нервной системы, а также их молекулярные механизмы являются только начальным этапом изучения данной проблемы. Необходимо продолжение исследований, в частности, поиск эффективных средств для терапии и профилактики указанных 
патологий на основании ранее не изученных механизмов патогенеза. Особенно значима популяризация этого нового взгляда на кишечную микробиоту и ее взаимосвязь с иммунопатологическими заболеваниями с целью привлечения исследователей для активного изучения проблемы.

\section{ЛИТЕРАТУРА}

1. Основы патологии заболеваний по Роббинсу и Котрану / Кумар В., Аббас А.К., Фаусто Н., Астер Дж. К.; пер. с англ.; под ред. Е.А. Коган. В 3 т. Том 1: главы 1-10.- М.: Логосфера, 2014. - 624 с.— - глава 8

2. Ke Y, Li D, Zhao M, Liu C, Liu J, Zeng A, Shi X, Cheng S, Pan B, Zheng L, Hong H. Gut flora-dependent metabolite Trimethylamine-N-oxide accelerates endothelial cell senescence and vascular aging through oxidative stress. Free Radic Biol Med. (2018) Feb 20;116:88-100. doi: 10.1016/j.freeradbiomed.2018.01.007.

3. Kowalski K., Mulak A. Brain-Gut-Microbiota Axis in Alzheimer's Disease // J Neurogastroenterol Motil. 2019 Jan; 25(1): 48-60. Published online 2019 Jan 1. doi: $10.5056 /$ jnm 18087

4. Медицинская микробиология, вирусология и иммунология: Учебник для студентов медициинских вузов / Под. ред. А.А. Воробьева. - 2-е изд., испр. И доп. - М.: 000 «Медицинское информационное агентство», 2012. — 704 с.: ил., табл. Стр. 88-93

5. Wopereis H, Sim K, Shaw A, Warner J0, Knol J, Kroll JS. Intestinal microbiota in infants at high risk for allergy: Effects of prebiotics and role in eczema development. J Allergy Clin Immunol. 2018 Apr;141(4):1334-1342.e5. doi: 10.1016/j.jaci.2017.05.054.

6. van den Elsen LWJ, Garssen J, Burcelin R, Verhasselt V. Shaping the Gut Microbiota by Breastfeeding: The Gateway to Allergy Prevention? Front Pediatr. 2019 Feb 27;7:47. doi: 10.3389/fped.2019.0004

7. Yu J, Luo Y, Zhu Z, Zhou Y, Sun L, Gao J, Sun J, Wang G, Yao X, Li W. A tryptophan metabolite of the skin microbiota attenuates inflammation in patients with atopic dermatitis through the aryl hydrocarbon receptor. J Allergy Clin Immunol. 2018 Dec 20. pii: S0091-6749(18)32777-5. doi: 10.1016/j.jaci.2018.11.036.

8. Boutin RCT, Dwyer Z, Farmer K, Rudyk C, Forbes MR, Hayley S. Perinatal antibiotic exposure alters composition of murine gut microbiota and may influence later responses to peanut antigen. Allergy Asthma Clin Immunol. 2018 Nov 1;14:42. doi: 10.1186/s13223-018-0263-8

9. Ransohoff RM. How neuroinflammation contributes to neurodegeneration. Science. 2016 Aug 19;353(6301):777-83. doi: 10.1126/science.aag2590

10. Kempuraj D, Thangavel R, Natteru PA, Selvakumar GP, Saeed D, Zahoor H, Zaheer S, lyer SS, Zaheer A. Neuroinflammation Induces Neurodegeneration. J Neurol Neurosurg Spine. 2016;1(1)

11. McManus RM, Heneka MT. Role of neuroinflammation in neurodegeneration: new insights. Alzheimers Res Ther. 2017 Mar 4;9(1):14. doi: 10.1186/s13195017-0241-2

12. Angelova PR, Abramov AY. Alpha-synuclein and beta-amyloid — different targets, same players: calcium, free radicals and mitochondria in the mechanism of neurodegeneration. Biochem Biophys Res Commun. 483(4):1110-1115. (2017)

13. Yao YY, Bian LG, Yang P, Sui Y, Li R, Chen YL, Sun L, Ai QL, Zhong LM, Lu D. Gastrodin attenuates proliferation and inflammatory responses in activated microglia through Wnt/B-catenin signaling pathway. Brain Res. 2019 Apr 23. pii: S0006-8993(19)30226-4. doi: 10.1016/j.brainres.2019.04.025

14. Dora Brites, Adelaide Fernandes. Neuroinflammation and Depression: Microglia Activation, Extracellular Microvesicles andmicroRNA Dysregulation. Front Cell Neurosci. 2015; 9: 476. doi: 10.3389/fncel.2015.00476

15. Marta Sochocka, Katarzyna Donskow-Łysoniewska, Breno Satler Diniz, Donata Kurpas, Ewa Brzozowska, Jerzy Leszek. The Gut Microbiome Alterations and Inflammation-Driven Pathogenesis of Alzheimer'sDisease — a Critical Review. Mol Neurobiol. 2019; 56(3): 1841-1851. doi: 10.1007/s12035-018-1188-4

16. Kristina A. Kigerl, Klauss Mostacada, Phillip G. Popovich. Gut Microbiota Are Disease-Modifying Factors After Traumatic Spinal Cord Injury. Neurotherapeutics. 2018 Jan; 15(1): 60-67. doi: 10.1007/s13311-017-0583-2

17. Paysour MJ, Bolte AC, Lukens JR. Crosstalk Between the Microbiome and Gestational Immunity in Autism-Related Disorders. DNA Cell Biol. 2019 Feb 28. doi: 10.1089/dna.2019.4653.

18. Minakova E, Warner BB. Maternal immune activation, central nervous system development and behavioral phenotypes. Birth Defects Res. 2018 Dec 1;110(20):1539-1550. doi: $10.1002 / b d r 2.1416$

19. Dabbah-Assadi F, Alon D, Golani I, Doron R, Kremer I, Beloosesky R, Shamir A. The influence of immune activation at early vs late gestation on fetal NRG1-ErbB4 expressionand behavior in juvenile and adult mice offspring. Brain Behav Immun. 2019 Feb 6. pii: S0889-1591(18)30422-7. doi: 10.1016/j.bbi.2019.02.002.

20. Bauman MD, Lesh TA, Rowland DJ, Schumann CM, Smucny J, Kukis DL, Cherry SR, McAllister AK, Carter CS. Preliminary evidence of increased striatal dopamine in a nonhuman primate model of maternal immune activation. Transl Psychiatry. 2019 Apr 12;9(1):135. doi: 10.1038/s41398-019-0449-y

21. Lammert CR, Lukens JR. Modeling Autism-Related Disorders in Mice with Maternal Immune Activation (MIA). Methods Mol Biol. 2019;1960:227-236. doi: 10.1007/978-1-4939-9167-9_20

22. Kang DW, Adams JB, Coleman DM, Pollard EL, Maldonado J, McDonough-Means S, Caporaso JG, Krajmalnik-Brown R. Long-term benefit of Microbiota Transfer Therapy on autism symptoms and gut microbiota. Sci Rep. 2019 Apr 9;9(1):5821. doi: 10.1038/s41598-019-42183-0.

23. Wang X, Yang J, Zhang H, Yu J, Yao Z. Oral probiotic administration during pregnancy prevents autism-related behaviors in offspring induced by maternal immune activation via anti-inflammation in mice. Autism Res. 2019 Apr;12(4):576-588. doi: 10.1002/aur.2079.

(с) Еременко Иван Иванович ( dvavani@mail.ru).

Журнал «Современная наука: актуальные проблемы теории и практики» 